\title{
STUDI KEKUATAN STABILITAS ABUTMENT PADA JALAN TOL PANDAAN - MALANG STA 15 + 916 TERHADAP PENGARUH GEMPA SESUAI DENGAN SNI 2833 - 2016
}

\author{
(Studi Kasus: Jalan Tol Pandaan - Malang Sta 15 + 916, Pasuruan - Jawa Timur) \\ Lilonna Ayu Heragita ${ }^{1}$, Pujo Priyono² ${ }^{2}$ Suhartinah $^{3}$ \\ Program Studi Teknik Sipil, Fakultas Teknik, Universitas Muhammadiyah Jember ${ }^{1,2,3}$ \\ Jl. Karimata 49,Jember 68121, Indonesia \\ email : heragita484@gmail.com
}

\begin{abstract}
Structurally the bridges are separated into upper buildings and lower buildings. According to its function, the building under the bridge supports and continues the load from the building over the bridge to a strong and stable / solid soil layer. The building under the bridge consists of abutments and foundations, where abutments can also function as a bridge foundation. The method used to analyze the stability of the abutment in this study is the approach method based on SNI 2833 - 2016 earthquake bridge. Then the stability is analyzed with the condition that it must meet the $S F$ safety factor values Slide punch>Pu, SF Bolster $>2.5$, SF carrying capacity borepile Pijin> Pmaks. From the analysis of the stability of strength that has been carried out in this case study states that the pons shear analysis value leaves a percentage ratio of 46.82 $\%$, the value of the $x$ direction bolster stability leaves a percentage ratio of $7.41 \%$, and the carrying capacity of bore pile leaves a percentage ratio amounting to $34.45 \%$.
\end{abstract}

Keywords: Stability against punch slides, x direction bolsters, and bearing strength bore pile.

\begin{abstract}
Abstrak
Secara struktural jembatan dipisahkan menjadi bangunan atas dan bangunan bawah. Sesuai fungsinya, bangunan bawah jembatan menopang dan meneruskan beban dari bangunan atas jembatan ke lapisan tanah yang kuat dan stabil/solid. Bangunan bawah jembatan terdiri dari abutmen dan pondasi, dimana abutmen bisa juga berfungsi sebagai pondasi jembatan. Metode yang digunakan untuk analisis kestabilan abutmen pada penelitian ini adalah metode pendekatan berdasarkan SNI 2833 - 2016 gempa jembatan. Kemudian dianalisa kestabilannya dengan syarat harus memenuhi nilai faktor keamanan SF Geser pons > Pu, SF Guling >2,5, SF daya dukung borepile Pijin > Pmaks. Dari analisis kekuatan stabilitas yang telah dilakukan pada studi kasus ini menyatakan bahwa nilai analisis geser pons menyisakan ratio presentase sebesar $46,82 \%$, nilai stabilitas guling arah x menyisakan ratio presentase sebesar 7,41\%, dan nilai kekuatan daya dukung bore pile menyisakan ratio presentase sebesar 34,45\%.
\end{abstract}

Kata kunci: Kestabilan terhadap geser pons, guling arah x, dan kekuatan bore pile.

\section{PENDAHULUAN}

\section{Latar Belakang}

Jembatan merupakan struktur yang sangat penting untuk menghubungkan sungai, selat, lembah, laut, dan lainnya. Sehingga dapat memperlancar transportasi darat dimana dengan adanya jembatan dapat mempersingkat waktu perjalanan.

Untuk menunjang ekonomi masyarakat secara keseluruhan dan berkesinambungan, sangat perlu adanya sarana dan prasarana infrastruktur diantaranya meningkatkan layanan jalan guna memperlancar laju pertumbuhan ekonomi di semua sektor. Dalam upaya mendukung kemudahan akses, pemerintah merencanakan pembangunan jalan tol Pandaan - Malang.

Terkait kemampuan jembatan pada stabilitas kekuatan abutment menerima beban, diantaranya adalah beban gempa serta dipengaruhi 3 lempengan tektonik yang terletak di Indonesia. Mengenai pengaruh beban gempa 
pada stabilitas kekuatan abutment menurut SNI 2833-2013 harus diperhitungkan dan diproyeksikan dalam perencanaan struktur bawah jembatan.

Maka dalam kesempatan Tugas Akhir kali ini, Penulis tertarik mengambil topik permasalahan tentang perencanaan jembatan yakni dengan mengambil judul "Studi Kekuatan Stabilitas Abutment Pada Jalan Tol Pandaan Malang Sta 15 + 916 Terhadap Pengaruh Gempa Sesuai dengan SNI 2833-2016".

\section{Rumusan Masalah}

Dari uraian diatas, masalah yang akan dibahas dalam Tugas Akhir ini adalah sebagai berikut:

1. Bagaimana pengaruh stabilitas geser dan guling terhadap konstruksi abutment STA $15+916$ di jalan tol Pandaan - Malang?

2. Berapa besar kekuatan bore pile menahan beban kekuatan akibat struktur jembatan pada STA $15+916$ di jalan tol Pandaan Malang?

\section{Tujuan Penelitian}

1. Untuk mengetahui perhitungan stabilitas geser dan guling pada abutment.

2. Untuk mengetahui kekuatan bore pile yang menahan beban keseluruhan akibat beban struktur jembatan.

\section{Batasan Masalah}

Beberapa batasan masalah yang didefinisikan dalam pembuatan Tugas Akhir antara lain:

1. Aspek yang ditinjau adalah jembatan Jalan Tol Pandaan - Malang STA $15+$ 916 , meliputi aspek kontruksi jembatan, perhitungan struktur jembatan, gambar kontruksi.

2. Perancangan pada struktur abutment jembatan Jalan Tol Pandaan - Malang STA $15+916$ serta kombinasi yang didalamnya terdapat faktor beban gempa.

3. Tidak menghitung dan menganalisis sambungan dan manajemen proyek

\section{Manfaat}

1. Untuk memberikan manfaat dan informasi secara lebih detail tentang kekuatan stabilitas geser dan guling pada struktur bawah jembatan.

2. Dari hasil perhitungan analisis struktur bawah jembatan Jalan Tol Pandaan Malang STA $15+916$, maka diharapkan dapat mengetahui pengaruh stabilitas geser dan guling pada abutment serta kekuatan borepile.

\section{METODE PENELITIAN}

\section{Definisi Jembatan}

Jembatan ialah suatu konstruksi yang gunanya untuk meneruskan jalan melalui suatu rintangan yang berada lebih rendah. Rintangan ini biasanya jalan lain ( jalan air atau jalan lalu lintas). Jembatan yang merupakan bagian dari jalan, sangat diperlukan dalam sistem jaringan transportasi darat yang akan menunjang pembangunan pada daerah tersebut (Struyk, 1984).

Secara garis besar konstruksi jembatan terdiri dari dua komponen utama yaitu bangunan atas (super structure/upper structure) dan bangunan bawah (sub structure). Bangunan atas merupakan bagian jembatan yang menerima langsung beban dari orang dan kendaraan yang melewatinya. Bangunan atas terdiri dari komponen utama yaitu lantai jembatan, rangka utama, gelagar melintang, gelagar memanjang,diafragma, pertambatan dan perletakan/andas. Selain itu juga terdapat kompenen penunjang pada bangunan atas yaitu trotoir, perlengkapan sambungan, ralling, pagar jembatan, drainase, penerangan dan parapet. Bangunan bawah merupakan bagian jembatan yang menerima beban dari bangunan atas ditambah tekanan tanah dan gaya tumbukan dari perlintasan di bawah jembatan. Bangunan bawah meliputi pilar jembatan (pier), pangkal jembatan (abutment) dan pondasi.

Secara umum konstruksi abutment terdiri dari beberapa bagian, aapun bagian-bagian konstruksi abutment terdiri dari:

1. Pile Cap (Pelat Dasar) terdiri dari tumpuan muka dan tumpuan belakang, pelat dasr ini juga disebut footing slab. Apabila menggunakan 
pondasi tiang pancang (Spun Pile) ataupun pondasi sumuran (Bore Pile), maka pelat dasar ini berfngsi untuk mengikat dan menyatukan antara abutment dengan tiang (pile).

2. Breast Wall

Disebut juga tembok longitudinal, dimana kontruksi ini harus mampu menerima gaya horizontal akibat tekanan tanah aktif dan tekanan tanah pasif, gaya gempa, seta menyeluruh gaya vertikal yang bekerja.

3. Tempat Sepatu

kontruksi tempat perletakan dari gelagar memanjang maupun melintang.

4. Perletakan (Elastomeric bearing pad) bantalan yang berfungsi untuk mengurangi getaran yang terjadi pada gelagar akibat beban dan kendaraan yang bergerak. Getaran tersebut kemudian diteruskan ke dinding abutment untuk kemudian diteruskan ke pondasi.

5. Back Wall

kontruksi dinding yang berfungsi sebagai pembatas antara gelagar dengan tanah belakang abutment.Selain itu juga, back wall berfungsi sebagai penahan gelagar agar tidak bergeser ke arah belakang abutment.

6. Wing Wall

berfunsi untuk melindungi bagian belakang abutment dari tekanan tanah yang bekerja.

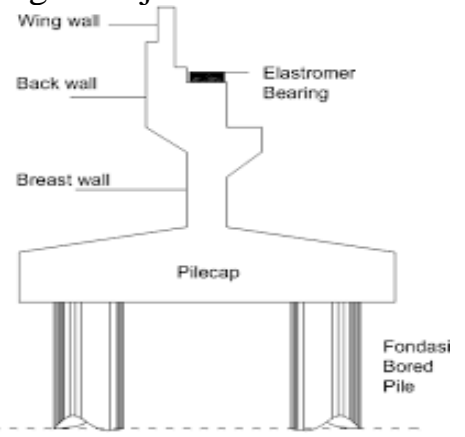

Gambar 1. Bagian-bagian Pada Abutment

\section{Kriteria Perencanaan Abutment}

Pada perencanaan abutment jembatan ini akan diperhitungkan banyak gaya dan beban yang bekerja pada abutment tersebut.

Gaya-gaya tersebut dapat digambarkan sebagai berikut:

\section{Gaya-gaya yang bekerja pada abutment}

- Gaya akibat beban mati

- Gaya Horisontal akibat gesekan tumpuan bergerak $(\mathrm{Hg})$ Koifisien gesekan $=0,25$ (PPPJJR / 1987 pasal 2.6.2)

$\mathrm{H}$ gesekan $=$ koifisien gesekan $\mathrm{Rvd}$

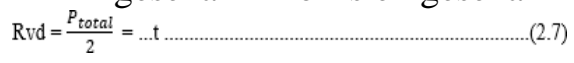

- Gaya akibat beban hidup

$\mathrm{R}_{\mathrm{QL}}=\overline{\overline{2}}$

$\mathrm{RpL}=\frac{P}{2,75} x k x l=\ldots$ ton.

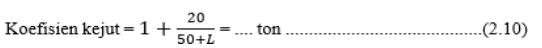

- Gaya akibat rem dan traksi Diperhitungkan 5\% dari beban D tanpa koifisien kejut dengan titik tangkap $1,8 \mathrm{~m}$ diatas permukaan lantai kendaraan (PPPJJR / 1987 hal 15).

- Gaya gempa akibat bangunan atas

Traksi Rrt $=\frac{5 \% x(R P Q+R q L)}{2}=\ldots$ ton ............................(2.11)

- Gaya horisontal tanah

Ka $=\operatorname{tg}^{2}\left(45^{\circ}-\frac{\phi}{2}\right) \ldots \ldots$

$\mathrm{Kp} \quad=\operatorname{tg}^{2}\left(45^{\circ}-\frac{\Phi}{2}\right)$

4. Hitungan daya dukung tanah dasar pondasi

Daya dukung tanah dasar pondasi berdasarkan rumus Tarzhagi untuk pondasi

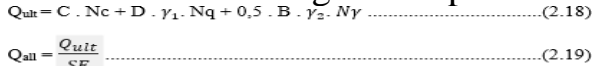

Perhitungan stabilitas abutment

- Syarat aman terhadap geser $\mathrm{SF}=\frac{\sum v \cdot \tan \frac{2}{2} \phi+c \cdot B}{\Sigma^{H}}$

- $\quad$ Syarat aman terhadap guling

$\mathrm{SF}=\frac{\Sigma M x}{\Sigma M y}$

- Syarat aman terhadap eksentrisitas

$\mathrm{e}=\frac{B}{2}-\frac{\sum M x_{-}^{-\Sigma M y}}{\Sigma v}<\frac{B}{6}$. ....(2.22)

- Kontrol terhadap tegangan

$\sigma=\frac{\Sigma_{v}}{B \cdot L}-\left[1 \pm \frac{6 \cdot e}{B}\right]$

$\sigma_{\text {mals }}=\mathrm{Q}_{\text {all }} \quad(\mathrm{OK})$

$\sigma_{\min } \leq$ Qall $\quad(\mathrm{OK})$

\section{Penulangan Abutment}

- Pelat Injak

Beban Sendiri plat injak $(w d)=$ Luasan $\mathrm{x}$ Berat jenis $(\mathrm{kN} / \mathrm{m})$

Beban Tanah timbunan $(\mathrm{wd})=$ Luasan 
$\mathrm{x}$ Berat jenis $(\mathrm{kN} / \mathrm{m})$

Berat aspal (wd)

Luasan $x$ Berat jenis $(\mathrm{kN} / \mathrm{m})$

Berat Kendaraan (wl)

Luasan x Berat jenis $(\mathrm{kN} / \mathrm{m})$

Didapat

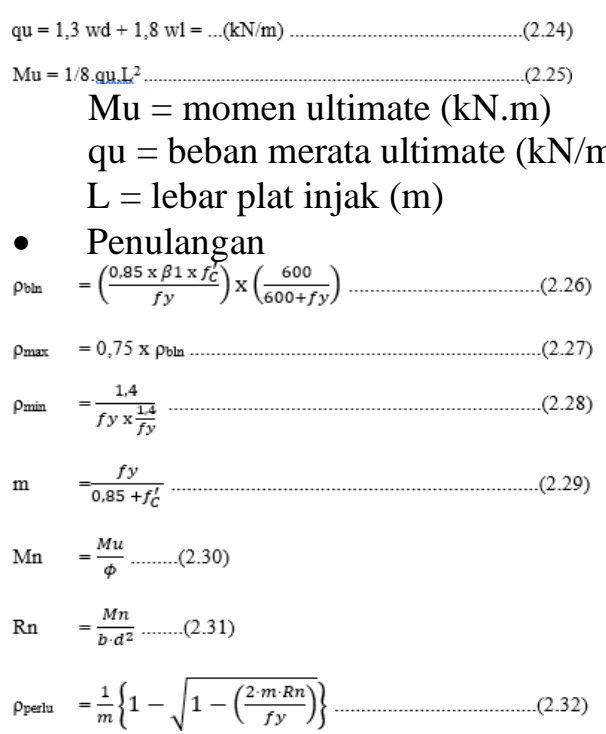

Jarak tulangan tekan dengan serat terluar

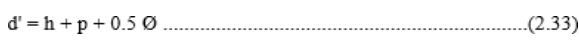

- Perhitungan Dinding Sayap

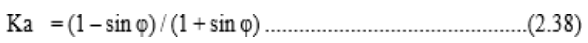

- Akibat tekanan tanah pada dinding $\mathrm{Tta1}=$ qux $\mathrm{xax}_{\mathrm{Ka}}$

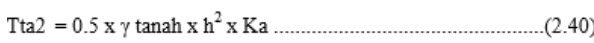

Tta $=$ Paq + Pah ...................................................... (2.41)

- Beban gempa statikekivalen

$\mathrm{T}_{\mathrm{BQ}}=\mathrm{Kh} \times \mathrm{I} \times \mathrm{Wt}=0,238875 \times \mathrm{Wt} \ldots \ldots \ldots \ldots \ldots \ldots \ldots \ldots \ldots \ldots \ldots \ldots . . .(2.43)$

- Tekanan tanah dinamis akibat gempa

$\mathrm{T}_{\mathrm{EQ} 2}=\mathrm{H} \times \mathrm{Ws} \times \Delta \mathrm{Ka}_{\mathrm{G}} \times \mathrm{By}$ (2.44)

\section{Perhitungan Pondasi Bore pile}

Untuk memprediksi besarnya kapasitas dukung selimut maupun kapasitas dukung ujung dapat dilakukan dengan menggunakan metode Reese \& Wright (1997) dan metode kulhawy. Kapasitas dukung ultimit pada ujung (Qp) tiang bor disajikan sebagai berikut :

$$
\begin{array}{ll}
Q_{p}=q_{p} \cdot A & \\
\text { Dimana } & \text { : } \\
\mathrm{Q}_{p} \quad=\text { Kapasitas dukung ultimit ujung tiang } \\
\mathrm{q}_{p} \quad=\text { Kapasitas dukung ultimit pada ujung tiang per satuan luas } \\
\left.\quad \text { (ton } / \mathrm{m}^{2}\right) \\
\mathrm{A} \quad=\text { Luas penampang tiang bor }\left(\mathrm{m}^{2}\right)
\end{array}
$$

Perhitungan kapasitas dukung selimut (Qs) tiang bor pada tanah homogen :

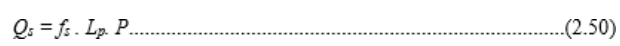

Untuk tanah kohesif menggunakan formula

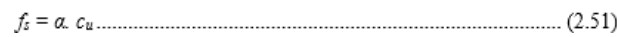

Jika tiang bor terletak pada tanah berlapis maka formula untuk memperoleh nilai kapasitas dukung ultimit selimut tiang (Qs) dapat dimodifikasi menjadi :

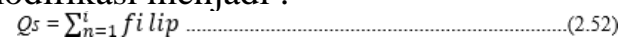

\section{Lokasi Proyek}

Lokasi proyek jalan tol Pandaan - Malang berada di Kabupaten Pasuruan dan Kabupaten Malang. Jembatan yang di tinjau berapa di seksi 2 STA 15 + 916 pada desa Parerejo, Kecamatan Purwodadi - Pasuruan.

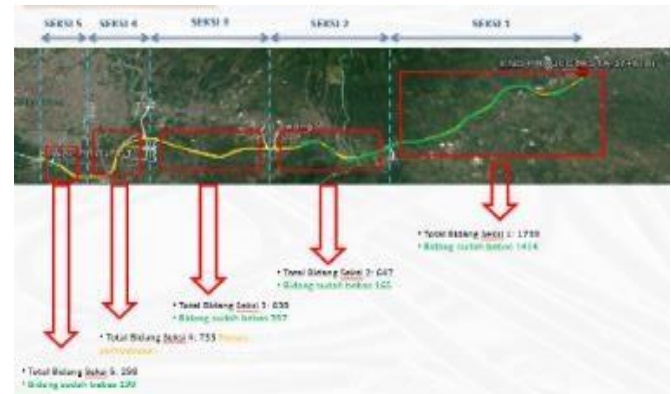

Gambar 2. Peta lokasi proyek

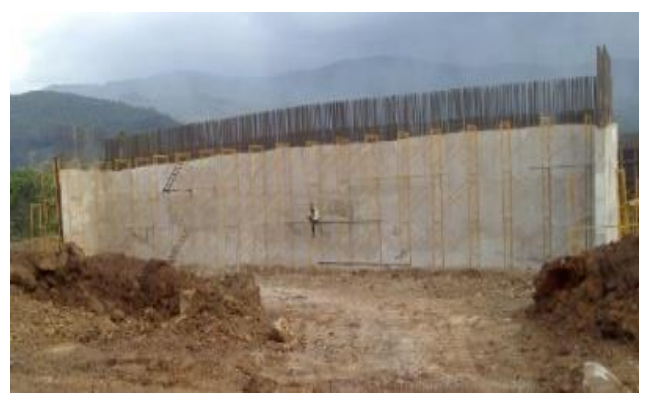

Gambar 3. Gambar Abutment 


\section{Kerangka Pemikiran}

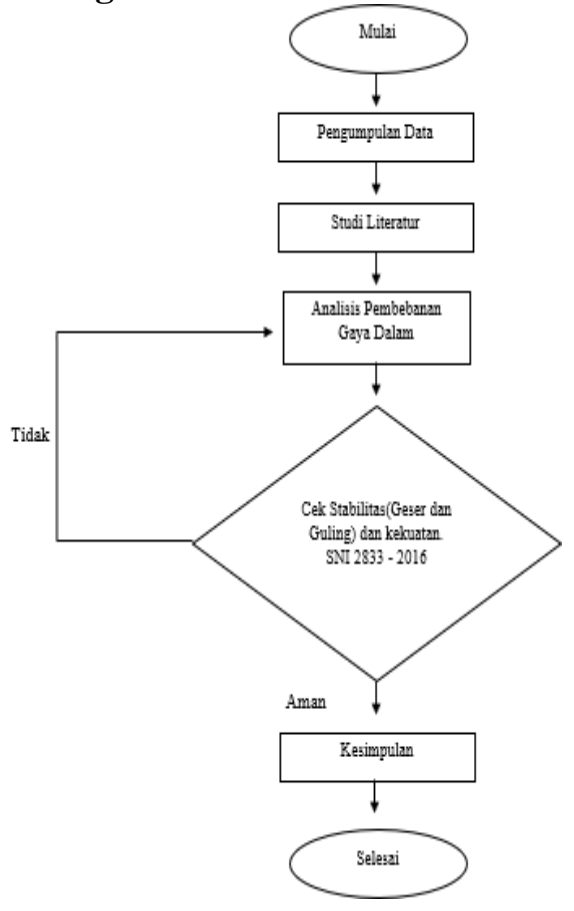

ANALISA DAN PEMBAHASAN

1. Analisa Perhitungan Pembebanan dan Momen Pada Abutment

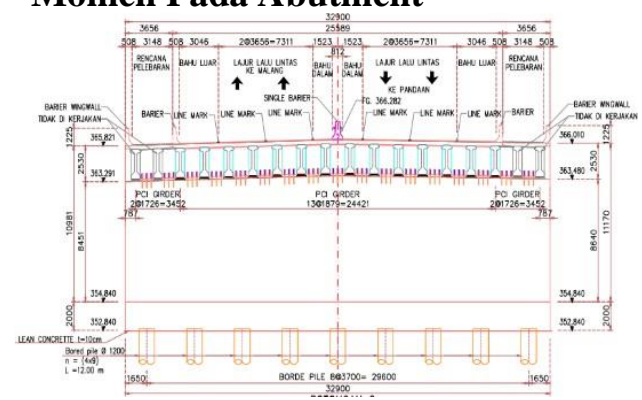

Gambar 4. Potongan Abutment

1. Data Struktur Atas

Uraian Dimensi :

- Tebal Slab Lantai $\quad=0.25 \mathrm{~m}$

- Tebal aspal+overlay $=0.10 \mathrm{~m}$

- Tebal lantai trotoar $=0.30 \mathrm{~m}$

- Tebal Genangan Hujan $=0.05 \mathrm{~m}$

- Jumlah Balok Utama $=18$ buah

- Jarak Antar Balok $=1.88 \mathrm{~m}$

- Lebar jalur lalu lintas $=15.54 \mathrm{~m}$

- Lebar Median $\quad=0.81 \mathrm{~m}$

- Lebar total $\quad=32.90 \mathrm{~m}$

- Panjang bentang $\quad=41.10 \mathrm{~m}$

- $\quad$ Tinggi bidang samping $=1.23 \mathrm{~m}$

- $\quad$ Tnggi girder prategang $=1.70 \mathrm{~m}$
Bahan Struktur :

- Mutu Beton : K 300

- Kuat Tekan : 24.9 Mpa

2. Analisis Beban Kerja

Dari perhitungan analisis beban kerja pada abutment didapatkan rekap beban kerja sebagai berikut :

Tabel 1. Rekap beban kerja

\begin{tabular}{|c|c|c|c|c|c|c|c|}
\hline \multicolumn{2}{|c|}{ REKAP BEBAN KERJA } & \multirow{2}{*}{\begin{tabular}{|l|} 
Arahh \\
Kode
\end{tabular}} & \multirow{2}{*}{$\begin{array}{c}\text { Vertikal } \\
\mathrm{P} \\
(\mathrm{kN})\end{array}$} & \multicolumn{2}{|c|}{ Horisontal } & \multicolumn{2}{|c|}{ Momen } \\
\hline No & AksiBeban & & & $\begin{array}{cc}\mathrm{Tx} \\
(\mathrm{k} N \mathrm{~N}\end{array}$ & $\begin{array}{cc}\mathrm{Ty} \\
\mathrm{GN}\end{array}$ & $\frac{\mathrm{Mx}}{\mathrm{MN}}$ & $\begin{array}{c}\mathrm{My} \\
(\mathrm{Ny}-\mathrm{m}\end{array}$ \\
\hline & Aksi tetap & & & & & & \\
\hline$\frac{1}{2}$ & Berat sendiri & MS & $\frac{58669,83}{176983}$ & & & $\frac{-160232.94}{2.2838,91}$ & \\
\hline$\frac{2}{3}$ & 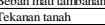 & $\frac{\mathrm{MA}}{\mathrm{TA}}$ & & 45288,09 & & $\frac{2288.31}{265411.48}$ & \\
\hline & Beban hath lintitas & & & & & & \\
\hline 4 & Benban hajur "D" & TD & 1786,03 & & & 0,00 & \\
\hline$\frac{5}{6}$ & $\begin{array}{l}\text { Beban pedestrian } \\
\text { eava rem }\end{array}$ & TP & 97,22 & 250,00 & & $\begin{array}{ll}0,00 \\
4230,00 \\
\end{array}$ & \\
\hline & Kksiling & & & & & & \\
\hline 7 & $\begin{array}{l}\text { Temperatur } \\
\text { Peprus }\end{array}$ & $\begin{array}{ll}\mathrm{ET} \\
\mathrm{EW} \\
\end{array}$ & 41,43 & & 10233 & $\frac{737,95}{0.00}$ & \\
\hline$\frac{8}{9}$ & $\begin{array}{l}\text { Bebananang } \\
\text { Beban gempa }\end{array}$ & $\begin{array}{ll}\text { EW } \\
\text { WQ } \\
\end{array}$ & & 19243.86 & $\frac{102.33}{15358.28}$ & $\begin{array}{l}13780 \\
13761,39 \\
\end{array}$ & $\frac{1278,76}{110025,43}$ \\
\hline 10 & Tek tanah dinar & & & 32543,77 & & 183546,89 & \\
\hline D. 11 & Aksihimya & $\mathrm{FB}$ & & 240569 & & 25596,59 & \\
\hline
\end{tabular}

3. Kontrol Stabilitas Guling

a. Stabilitas Guling Arah X

Pondasi tiang tidak diperhitungkan dalam analisis stabilitas terhadap guling, sehingga $\mathrm{SF}=2.5$

Letak titik guling A (ujung pondasi) terhadap pusat pondasi

$$
\mathrm{Bx} / 2=6.6185 \mathrm{~m}
$$

$\mathrm{k}=$ persen kelebihan beban yang diijinkan $(\%)$

$\mathrm{Mx}=$ momen penyebab guling arah $\mathrm{X}$

Momen penahan guling : $\mathrm{Mpx}=\mathrm{P} \mathrm{x}(\mathrm{Bx} / 2)$ $\mathrm{x}(1+\mathrm{k})$

Angka aman terhadap guling : $\mathrm{SF}=$ $\mathrm{Mpx} / \mathrm{Mx}$ harus $\geq 2.5$

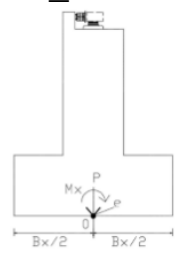

Tabel 2. Stabilitas Guling Arah X

\begin{tabular}{|c|l|c|c|c|c|c|c|}
\hline No & KOMBINASI BEBAN & $\mathrm{k}$ & $\begin{array}{c}\mathrm{P} \\
\mathrm{kN}\end{array}$ & $\begin{array}{c}\mathrm{Mx} \\
\mathrm{kNm}\end{array}$ & $\begin{array}{c}\mathrm{MPx} \\
\mathrm{kNm}\end{array}$ & SF & Keterangan \\
\hline 1 & KOMBINASI-1 & $0 \%$ & 62320,93 & 133288,933 & 412471,045 & 3,1 & $>2,5(0 \mathrm{~K})$ \\
\hline 2 & KOMBINASI-2 & $25 \%$ & 62362,354 & 192842,819 & 515931,552 & 2,7 & $>2,5(0 \mathrm{~K})$ \\
\hline 3 & KOMBINASI-3 & $40 \%$ & 62362,354 & 137518,933 & 577843,338 & 4,2 & $>2,5(0 \mathrm{~K})$ \\
\hline 4 & KOMBINASI-4 & $40 \%$ & 62362,354 & 138256,884 & 577843,338 & 4,2 & $>2,5(0 \mathrm{~K})$ \\
\hline 5 & KOMBINASI-5 & $50 \%$ & 60437,669 & 163659,144 & 600010,071 & 3,7 & $>2,5(0 \mathrm{~K})$ \\
\hline
\end{tabular}

\section{b. Stabilitas Guling Arah Y}

Letak titik guling A (ujung pondasi) terhadap pusat pondasi 


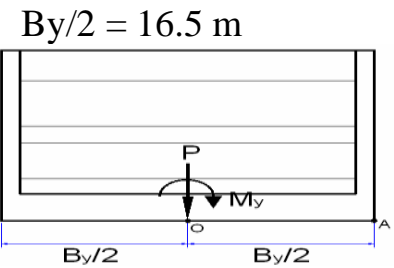

Tabel 3. Stabilitas Guling Arah Y

\begin{tabular}{|r|r|r|r|r|r|r|r|}
\hline No & KOMBINASI BEBAN & $\mathrm{k}$ & $\begin{array}{c}\mathrm{P} \\
\mathrm{kN}\end{array}$ & $\begin{array}{c}\mathrm{My} \\
\mathrm{kNm}\end{array}$ & $\begin{array}{c}\text { Mpy } \\
\mathrm{kNm}\end{array}$ & \multicolumn{1}{c|}{ SF } & Keterangan \\
\hline 1 & KOMBINASI-1 & $0 \%$ & 62320,925 & 0,000 & 1025179,22 & & \\
\hline 2 & KOMBINASI-2 & $25 \%$ & 62362,354 & 1278,760 & 1282325,91 & 1002,79 & $>2,5(\mathrm{OK})$ \\
\hline 3 & KOMBINASI-3 & $40 \%$ & 62362,354 & 1278,760 & 1436205,02 & 1123,12 & $>2,5(\mathrm{OK})$ \\
\hline 4 & KOMBINASI-4 & $40 \%$ & 62362,354 & 1278,760 & 1436205,02 & 1123,12 & $>2,5(0 \mathrm{~K})$ \\
\hline 5 & KOMBINASI-5 & $50 \%$ & 60437,669 & 110025,430 & 1491299,49 & 13,55 & $>2,5(0 \mathrm{~K})$ \\
\hline
\end{tabular}

4. Kontrol Stabilitas Guling

a. Stabilitas Geser Arah X

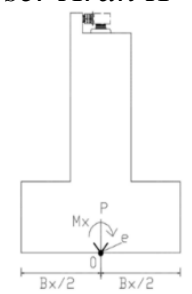

Parameter pile cap :

Sudut gesek dalam $\varphi=14^{\circ}$

Kohesi $\quad \mathrm{c}=0.16 \mathrm{kPa}$

Ukuran pile cap $\quad \mathrm{Bx}=13,2 \mathrm{~m}$

$\mathrm{By}=32.9 \mathrm{~m}$

$\mathrm{k}=$ persen kelebihan beban yang diijinkan (\%)

$\mathrm{Tx}=$ gaya penyebab geser

Gaya penahan geser :

$\mathrm{H}=(\mathrm{c} * \mathrm{Bx} * \mathrm{By}+\mathrm{P} * \tan \varphi) *(1+\mathrm{k})$ harus $>1.2$

Tabel 4. Stabilitas Geser Arah X

\begin{tabular}{|c|c|c|c|c|c|c|c|}
\hline No & KOMBNASI BEBAN & k & Is & P & H & $S F$ & Keteragen \\
\hline 1 & KOMBNASI-1 & $0 \%$ & 47693,783 & 623209254 & 155469,515 & 3,3 & $>12(20 \mathrm{~K})$ \\
\hline 2 & KOMBNASIL2 & $25 \%$ & 78081,863 & 0236233442 & 194486005 & 25 & $>12,2(\mathrm{OK})$ \\
\hline 3 & KOIBNASL-3 & $40 \%$ & 4743,78 & 023623342 & 217744076 & 45 & $>12(\mathrm{KK})$ \\
\hline 4 & XOMENNSILA & $40 \%$ & 40013.139 & 023623442 & 217744076 & 45 & $>12(\mathrm{OK})$ \\
\hline 5 & KOMGNNASL. 5 & $50 \%$ & 51787,64 & 60437,6093 & 2261234466 & 44 & $>12(\mathrm{OK})$ \\
\hline
\end{tabular}

b. Stabilitas Geser Arah Y

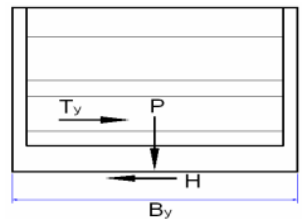

Parameter tanah dasar pile cap :

Sudut gesek dalam $\varphi=14^{\circ}$
Kohesi

$$
\mathrm{c}=0.16 \mathrm{kPa}
$$

Ukuran pile cap

$$
\mathrm{Bx}=13.24 \mathrm{~m}
$$$$
\mathrm{By}=32.9 \mathrm{~m}
$$

$\mathrm{k}=$ persen kelebihan beban yang diijinkan $(\%)$

$\mathrm{Tx}=$ gaya penyebab geser

Gaya penahan geser :

$\mathrm{H}=(\mathrm{c} * \mathrm{Bx} * \mathrm{By}+\mathrm{P} * \tan \varphi) *(1+\mathrm{k})$ harus $>1.2$

\begin{tabular}{|c|c|c|c|c|c|c|c|}
\hline No & KOABRASI BEBAN & k & $\begin{array}{l}\mathrm{Ty} \\
\mathrm{WN}\end{array}$ & $\begin{array}{c}\mathrm{P} \\
\mathrm{WN}\end{array}$ & $\begin{array}{l}\text { II } \\
\text { WN }\end{array}$ & $3 \Gamma$ & Keladigat \\
\hline 1 & KOMBDNASI-1 & $0 \%$ & 0 & Q2320,9254 & 15609,6632 & & \\
\hline 2 & KOMGDNASI.2 & $25 \%$ & 1023312 & Q23623342 & 19507,5721 & 190,63 & $>12(\mathrm{OK})$ \\
\hline 3 & KOABDNASI.3 & $40 \%$ & 1023312 & Q23623342 & 21840,1192 & 213,43 & $>12(\mathrm{OK})$ \\
\hline 4 & KOABDNASI-4 & $40 \%$ & 10233129 & Q23623542 & 21844,1192 & 213,43 & $>1,2(\mathrm{OK})$ \\
\hline 5 & KOMBNANST.5 & $50 \%$ & 153582285 & 60437,693 & 22675,2582 & 148 & $>12(\mathrm{KK})$ \\
\hline
\end{tabular}
Tabel 5. Stabilitas Geser Arah Y

\section{Analisis Beban Ultimit}

1. Pile Cap

Tabel 6. Rekap Kombinasi Beban

\begin{tabular}{|c|c|c|c|c|c|c|}
\hline No. & KOMBNASI BBAN & $\begin{array}{l}\mathrm{P}_{\mathrm{v}} \\
\text { (tiv) }\end{array}$ & $\begin{array}{l}\text { Tix } \\
\text { (av) }\end{array}$ & $\begin{array}{l}\text { Tyy } \\
\text { (avi) }\end{array}$ & $\begin{array}{l}\text { Minx } \\
\text { (aNm) }\end{array}$ & $\begin{array}{l}\text { Miny } \\
\text { (aving }\end{array}$ \\
\hline 1 & KOMBNAST-1 & 83428,23 & 57193,34 & 12280 & 137812,17 & 1534,51 \\
\hline 2 & KOMBNASI-2 & 83378,52 & 59590,0325 & 0 & 163408,7607 & 0 \\
\hline 3 & KOMBNASL-3 & 89428,23 & $\$ 9515,81$ & 12280 & 10252,23 & 153451 \\
\hline 4 & KOMBNAST-4 & 80.62 .68 & $571.93,4$ & 1.2280 & 137812.17 & 1534.51 \\
\hline & KOMBNNAS-5 & 7880645 & 782596 & 398.2 & 449874.9 & 110005 . \\
\hline
\end{tabular}
Ultimit Pile Cap

2. Breast Wall

a. Tekanan Tanah (TA)

$$
\begin{aligned}
& \mathrm{H}^{\prime}=14.92 \mathrm{~m} \quad \phi^{\prime}=0,3203 \mathrm{rad} \\
& \mathrm{Ka}=0.530152 \quad \mathrm{Ws}^{\prime}=17 \mathrm{kN} / \mathrm{m}^{3} \\
& 0.6 \text { x Ws }=10.2 \mathrm{kN} / \mathrm{m}^{3} \\
& \text { By }=32.9
\end{aligned}
$$

\begin{tabular}{|c|c|c|c|c|c|}
\hline No. & Gaya akibat tekannn tamh & $\begin{array}{r}\mathrm{T}_{\mathrm{TA}} \\
(\mathrm{kN})\end{array}$ & $\begin{array}{l}\text { Lengn } \\
\text { thd } 0\end{array}$ & $\begin{array}{c}y \\
\text { (m) }\end{array}$ & $\begin{array}{c}\mathrm{M}_{\mathrm{TA}} \\
(\mathrm{kNN})\end{array}$ \\
\hline 1 & TTA $=\left(0.60 * w^{*}\right)^{*} \mathrm{H}^{*} \mathrm{Ka}{ }^{*} \mathrm{By}$ & 265439 & $y=H / 2$ & 7,46 & 19801,770 \\
\hline 2 & $\mathrm{TTA}=1 / 2 * \mathrm{H} 2 * \mathrm{ws}^{*} \mathrm{Ka}^{*} \mathrm{By}$ & 33002,95 & $y=H / 3$ & 4,97 & 164134,673 \\
\hline & $I_{\tau u}=$ & 35657,34 & & $M_{T S}=$ & 183936,443 \\
\hline
\end{tabular}

Tabel 7. Gaya Akibat Tekanan Tanah

\begin{tabular}{|c|c|c|c|c|c|}
\hline No. & $\begin{array}{c}\text { Berat } \\
\text { Wt }(\mathrm{kN})\end{array}$ & $\begin{array}{l}\begin{array}{l}\text { EQQ } \\
\mathrm{EN}\end{array} \\
\end{array}$ & Urain lengan terha dap trik 0 & $\begin{array}{l}\text { Besar } \\
y(m)\end{array}$ & $\begin{array}{c}\text { MEQ } \\
(\mathrm{kNm})\end{array}$ \\
\hline \multicolumn{6}{|c|}{ STRUK TURATAS } \\
\hline Pine & 11597,14 & 3794,6517 & $y=H$ & 14,92 & 56616,203 \\
\hline$P_{m}$ & 1767,83 & 578,44578 & $y=H$ & 14,92 & 8630,411 \\
\hline \multicolumn{6}{|c|}{ BREASTWALL } \\
\hline 1 & 221,5618 & 72,496311 & $\mathrm{y} 1=\mathrm{c}+\mathrm{h} 4 \mathrm{4}+\mathrm{h} 3+\mathrm{h} 2 \mathrm{~h}+\mathrm{h} / 2$ & 14,46 & 1048,297 \\
\hline 2 & 387,7331 & $126,86854 \mathrm{x}$ & $\mathrm{y} 2 \mathrm{c}=\mathrm{c}+\mathrm{h}, 4+\mathrm{h}^{3}+\mathrm{h} 22 \mathrm{2}$ & 13,20 & 1674,030 \\
\hline 3 & 168,5796 & $55,160237 \mathrm{x}, \quad(2)$ & $83=c+t h 4+h 3 / 2$ & 12,04 & 664,129 \\
\hline 4 & 36,1242 & 11,820051 & $\mathrm{H} A=\mathrm{c}+2 B^{*} \mathrm{~h} 4$ & 11,59 & 136,994 \\
\hline 5 & 0 & 0 & $v^{5}=d+h 6+15 / 2$ & 0 & 0,000 \\
\hline 6 & 0 & 0 & $16=d+2 / 3^{*} h 6$ & 0,000 & 0,000 \\
\hline \multirow[t]{2}{*}{7} & $-3667,81$ & $-1200,129$ & $\mathrm{v} 7=h^{\prime} 72$ & $-1,525$ & 1830,197 \\
\hline & $\mathrm{T}_{\mathrm{BO}}=$ & 3439,3134 & & $\mathrm{M}_{\mathrm{EO}}=$ & 70600,262 \\
\hline
\end{tabular}

\section{b. Beban Gempa}

$\mathrm{T}_{\mathrm{EQ}}=\mathrm{Kh} \times \mathrm{I} \times \mathrm{Wt}=0.3272059 \times \mathrm{Wt}$

Tabel 8. Beban Gempa Pada Bagian Breast Wall 
c. Beban Ultimit Breast Wall

Tabel 9. Beban Ultimit Breast Wall

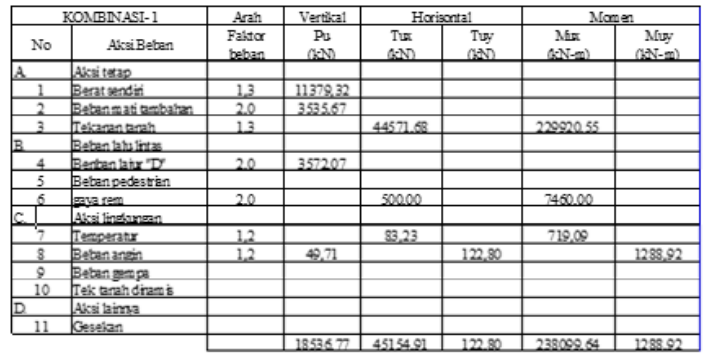

Tabel 10. Rekap Kombinasi Beban Ultimit Breast Wall

\begin{tabular}{|c|c|c|c|c|c|c|}
\hline Ne & KOMBDNASI BEBAN & $\begin{array}{c}\mathrm{P}_{4} \\
(\mathrm{kNN})\end{array}$ & $\begin{array}{l}\text { Tur } \\
\text { (aIN) }\end{array}$ & $\begin{array}{l}\text { Tuy } \\
\text { (kN) }\end{array}$ & 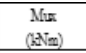 & $\begin{array}{c}\mathrm{N} \text { Nyy } \\
(\mathrm{kN})\end{array}$ \\
\hline 1 & KOMBNASI 1 & 1853677 & 45154,91 & 12280 & 238099,64 & 1288,92 \\
\hline 2 & KONBNASI- 2 & 18487,058 & 47560,6012 & 0 & 258884,8434 & 0 \\
\hline 3 & KONBNASI- 3 & 1853677 & 47477,37 & 12280 & 258165,76 & 1288,92 \\
\hline 4 & KOMBNASI-4 & 18925,67 & 45154,91 & 12280 & 238099,64 & 1288,92 \\
\hline 5 & KOMBNASI-5 & 14914,99 & 73770,61 & 3439,31 & 555612,43 & 70600,26 \\
\hline
\end{tabular}

3. Back Wall

Tabel 11. Beban Ultimit Back Wall Bawah

\begin{tabular}{|c|c|c|c|c|c|c|c|}
\hline \multirow{2}{*}{ No } & \multirow{2}{*}{ Aksibetan } & \multirow{2}{*}{$\begin{array}{l}\text { Kode } \\
\text { beban }\end{array}$} & \multirow{2}{*}{$\begin{array}{l}\text { Faldor } \\
\text { Beben }\end{array}$} & \multicolumn{2}{|c|}{ Besan Kejas } & \multicolumn{2}{|c|}{ BbosnClinit } \\
\hline & & & & $T^{T}$ & M & Tu & $\mathrm{Mw}$ \\
\hline & Akcitas tasp & & & & & & \\
\hline 1 & Berat enditi & & & & & & \\
\hline 2 & Betaen mati anbahin & & & & & & \\
\hline 3 & 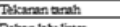 & $\mathrm{IA}$ & 1,25 & 1399,09 & 1309,69 & 1748,86 & 1712,11 \\
\hline & Beben lats inrex & & & & & & \\
\hline$\frac{4}{6}$ & Berban laju D D & & & & & & \\
\hline$\frac{5}{6}$ & 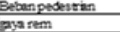 & & & & & & \\
\hline & Acilingaren & & & & & & \\
\hline$\frac{7}{8}$ & Demperast & & & & & & \\
\hline$\frac{8}{9}$ & 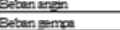 & $\mathrm{BO}$ & 1,0 & 199,4 & 2522 & 199,4 & 2522 \\
\hline 10 & Der anahdramb & EQ & 10 & 39992 & 5365,8 & 30992 & 5365,8 \\
\hline & Akesiams & & & & & & \\
\hline 11 & Gevetion & & & 5807 & 8087 & 00974 & 73013 \\
\hline
\end{tabular}

Tabel 12. Beban Ultimit Back Wall Atas

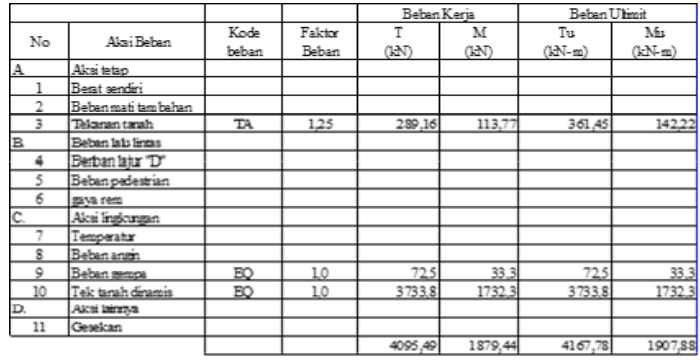

4. Wing Wall

Tabel 13. Beban Ultimit Wing Wall

\begin{tabular}{|c|c|c|c|c|c|}
\hline No & Aksi.Beban & $\begin{array}{l}\begin{array}{l}\text { Faktor } \\
\text { beban }\end{array} \\
\text { ton }\end{array}$ & $\begin{array}{c}\mathrm{Vu} \\
(\mathrm{kN})\end{array}$ & $\begin{array}{c}\text { Muy } \\
(\mathrm{kN}-\mathrm{m})\end{array}$ & $\begin{array}{c}\text { Mux } \\
(\mathrm{kN}-\mathrm{m})\end{array}$ \\
\hline A. & Aksi tetap & & & & \\
\hline 1 & Berat sendiri & & & & \\
\hline 2 & Beban mati tambahan & & & & \\
\hline 3 & Tekanan tanah & 1,25 & 10380,19 & 53545,63 & 39766,5023 \\
\hline B. & Beban lalu lintas & & & & \\
\hline 4 & Beban lajur "D" & & & & \\
\hline 5 & Beban pedestrian & & & & \\
\hline 6 & gaya rem & & & & \\
\hline C. & Aksi lingkungan & & & & \\
\hline$\frac{7}{8}$ & Temperatur & & & & \\
\hline$\frac{8}{9}$ & \begin{tabular}{|l|} 
Beban angin \\
Beban gempa
\end{tabular} & & & & $1375,67-2$ \\
\hline 10 & Tek tanah dinamis & 1,0 & 5999,09 & 59407,66 & 22982,53 \\
\hline D. & Aksi lainnya & & & & \\
\hline 11 & Gesekan & & & & \\
\hline & & & 16738,37 & 115632,10 & 64124,70 \\
\hline
\end{tabular}

\section{Analisis Pondasi Abutment}

Data Material Pondasi

Bahan Material Pondasi :

- Mutu beton

K-350

- Kuat tekan beton

$$
\mathrm{f}^{\prime} \mathrm{c}=29.5 \mathrm{Mpa}
$$

- Mutu baja tulangan U-39

- Tegangan leleh baja

$$
\text { fy }=390 \mathrm{MPa}
$$

- Modulus elastisitas beton

$$
\mathrm{Ec}=25332.084 \mathrm{MPa}
$$

- Berat beton bertulang

$$
\mathrm{wc}=24.00 \mathrm{kN} / \mathrm{m} 3
$$

Pondasi End Bearing Dan Friction :

- Berat volume tanah

$$
\mathrm{ws}=23 \mathrm{kN} / \mathrm{m} 3
$$

- Sudut gesek dalam $\phi=44^{\circ}$

- Kohesi tanah, c $=10 \mathrm{kPa}$

Dimensi Pile Cap :

- Lebar arah $\mathrm{x}, \mathrm{Bx}=13.2 \mathrm{~m}$ Tebal, $\mathrm{hp}=2.00 \mathrm{~m}$

- Lebar arah y, By $=32.9 \mathrm{~m} \quad$ Tebal, ht $=2.00 \mathrm{~m}$

Dimensi tiang Bore Pile :

- Diameter luar $\mathrm{D}=0.8 \mathrm{~m}$

- Panjang, $\mathrm{L}=12.0 \mathrm{~m}$

Jarak pusat tiang pancang terluar terhadap sisi luar Pile cap a $=1.65 \mathrm{~m}$

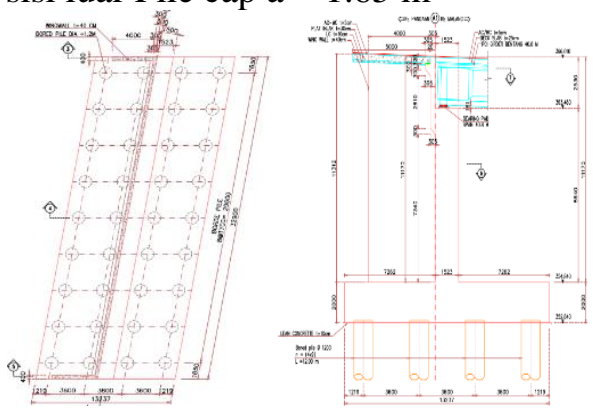

Gambar 5. Denah Bore Pile \& Detail Abutment

Data Susunan Bore Pile :

- Jumlah baris tiang ny $=9$

- Jumlah tiang dalam satu baris $\mathrm{nx}=4$

- Jarak antara tiang dalam arah $X$ $\mathrm{X}=3.6 \mathrm{~m}$

- Jarak antara tiang dalam arah $\mathrm{Y}$ $\mathrm{Y}=3.7 \mathrm{~m}$ 
1. Rekap Daya Dukung Aksial Tiang

Untuk daya dukung aksial tiang diambil berdasarkan kekuatan bahan yaitu 4782.17 $\mathrm{kN}$.

Jumlah baris tiang, ny $=19$

Jumlah tiang dalam satu baris, $\mathrm{nx}=4$ Jarak antara tiang, $\mathrm{X}(\mathrm{m})=3.6$

$$
\mathrm{Y}(\mathrm{m})=3.7
$$

Jarak antara tiang terkecil, $\mathrm{S}=3.6$

Jarak antar tiang $\mathrm{Sb}=3.7 \mathrm{~m}$, harus $<6.166$ ok!

Diameter Tiang, $\mathrm{D}=1.2 \mathrm{~m}$

Efisiensi kelompok tiang(menurut BDM)

Eff $=0.6643$

$$
\mathrm{P} \text { ijin }=10014.53 \mathrm{kN}
$$

Diambil daya dukung aksial ijin tiang :

$\mathrm{P}$ ijin $=10014.53 \mathrm{kN}$

2. Daya Dukung Lateral Ijin Tiang

Kedalaman ujung tiang,

$$
\mathrm{La}=\mathrm{hp}=2 \mathrm{~m}
$$

Sudut gesek, $\phi=40^{\circ}$

Panjang Tiang $\mathrm{L}=12 \mathrm{~m}$

Panjang jepitan tiang, $\mathrm{Ld}=4 \mathrm{~m}, \mathrm{By}=32.9$,

$\mathrm{Ws}=23 \mathrm{kN} / \mathrm{m} 3$

Koifisien tekanan tanah pasif,

$\mathrm{Kp}=\tan 2\left(45^{\circ}+\phi / 2\right)=5.5537$

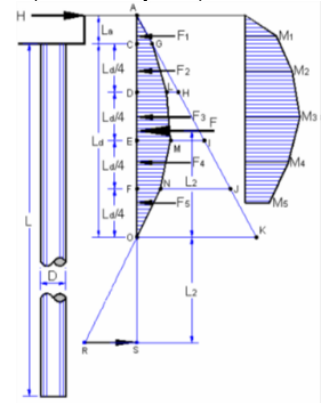

Gambar 6. Diagram Tekanan Tanah Pasif

3. Kontrol Daya Dukung Ijin Tiang

- Daya Dukung Ijin Aksial

\begin{tabular}{|c|c|c|c|c|c|c|}
\hline No. & $\begin{array}{l}\text { KOUBNAS } \\
\text { BEBAN KER }\end{array}$ & $\begin{array}{l}\text { Persen } \\
\text { Pinn }\end{array}$ & $\begin{array}{l}P_{\text {and }} \\
\mathrm{WV}\end{array}$ & $\begin{array}{c}\text { Kontrol the } \\
\text { Daya dukngng in }\end{array}$ & $\begin{array}{l}\mathrm{P}_{\mathrm{m}} \\
\mathrm{EN}\end{array}$ & Reter \\
\hline 1 & KOUBNASI-1 & $100 \%$ & 2965,293606 & $<100 \% * \mathrm{P}=$ & 10014,5 & Aman \\
\hline 2 & KOVBANASI-2 & $125 \%$ & 3517,869272 & $<125 \% \%^{*} \mathrm{P}$ 的 $=$ & 12518,2 & Aman \\
\hline 3 & KONBAASI-3 & $140 \%$ & 3005,611072 & $<1400 \%$ P P $\mathrm{F}=$ & 14020,3 & $A$ man \\
\hline 4 & KOVBIAASI-4 & $140 \%$ & 3012,43947 & $<140 \%:{ }^{*} \mathrm{P}=$ & 14020,3 & $A \operatorname{man}$ \\
\hline 5 & KOVBNASI-5 & $150 \%$ & 3376,300173 & $<150 \% * \mathrm{P} ; \mathrm{y}=$ & 15021,8 & Aman \\
\hline
\end{tabular}

Tabel 14. Perhitungan daya dukumg aksial terhadap beban arah X
Tabel 15. Perhitungan daya dukumg aksial terhadap beban arah Y

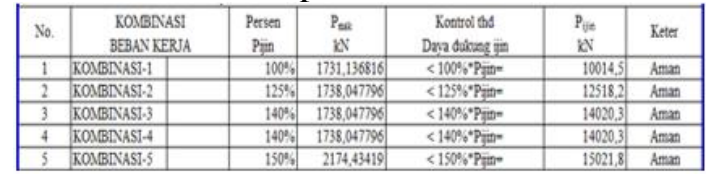

4. Daya Dukung Ijin Lateral

Dari perhitungan pondasi diatas didapat

\begin{tabular}{|c|c|c|c|c|c|c|}
\hline No & $\begin{array}{l}\text { RONGS } \\
\text { RERAN! }\end{array}$ & $\begin{array}{c}\text { Pesen } \\
\text { Pint }\end{array}$ & mak & 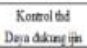 & 40 & Keter \\
\hline 1 & KOXGIXSL! & 1000 & 1324,827906 & $<10055^{\circ} z_{2}=$ & 4709,65 & $A_{\min }$ \\
\hline 2 & KONBINASL-2 & 1250 & 2168940638 & 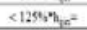 & 5857,06 & $A_{\operatorname{man}}$ \\
\hline 3 & Rosanus: & 1005 & 1331,77175 & 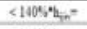 & 6990,31 & $\operatorname{Amm}$ \\
\hline 4 & KONGINASL- & 10050 & 1333,6983113 & $<\left.1400^{\circ}\right|^{1 / c^{\circ}}$ & 65993,51 & $A_{\min }$ \\
\hline 1 & KOManusis & $15 \%$ & 1514,408499 & 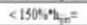 & 7064,47 & $A_{\max }$ \\
\hline
\end{tabular}
daya dukung lateral ijin pondasi bore pile Tabel 16. Daya dukung ijin lateral

- Geser Pons

Kuat geser pons yang disyaratkan, $\mathrm{fv}=$ $1.497 \mathrm{Mpa}$

Faktor redusi, $\varphi=0,6$

$\mathrm{nx}=3600 \mathrm{~mm}, \mathrm{ny}=3700 \mathrm{~mm}$

$\mathrm{a}=1650 \mathrm{~mm}$

$\mathrm{r}=\mathrm{r} / \mathrm{x}=1800 \mathrm{~mm}$

$\mathrm{r}=\mathrm{y} / \mathrm{x}=1850 \mathrm{~mm}$

maka diambil, $\mathrm{r}=1000 \mathrm{~mm}, \mathrm{hp}=2000$

$\mathrm{mm}, \mathrm{ht}=2000 \mathrm{~mm}, \mathrm{Lt}=7262 \mathrm{~mm}$

Tebal bidang kritis geser pons

$\mathrm{h}=2000 \mathrm{~mm}$

Panjang total bidang kritis

$\mathrm{Lv}=68771.43$

tebal efektif bidang kritis geser pons $\mathrm{d}=$ $1900 \mathrm{~mm}$

Luas bidang geser

Av $=13742857.14 \mathrm{~mm}^{2}$

Gaya geser pons nominal

$\mathrm{Pn}=20573015.8 \mathrm{~N}$

$\varphi \mathrm{Pn}=12343.8 \mathrm{kN}$

Beban ultimit satu tiang

$\mathrm{Pu}=6564.5 \mathrm{~N}<\varphi \mathrm{Pn}$ Aman $(\mathrm{OK})$

\section{KESIMPULAN DAN SARAN}

\section{Kesimpulan}

1. Analisis perhitungan stabilitas abutment terhadap pengaruh Gempa Sesuai dengan SNI 2833- 2016:

- Analisis geser pons dengan gaya geser pons nominal, $\varphi$ Pn adalah $12343.8 \mathrm{kN}$, dan pada analisis nilai beban ultimit satu borepile, $\mathrm{Pu}$ adalah 6564.5, sehingga geser pons 
menyisakan ratio persentase kekuatan sebesar $46.82 \%$.

- Analisis stabilitas guling arah x dengan nilai safety factor adalah 2.5, dan pada analisis nilai safety factor maksimum adalah

2.7 yakni pada kombinasi I, sehingga stabilitas guling arah $\mathrm{x}$ menyisakan ratio persentase kekuatan sebesar $7.41 \%$.

2. Analisis kekuatan borepile dengan daya dukung aksial borepile, $\mathrm{Pijin}$ adalah $10015 \mathrm{kN}$, dan pada analisis nilai gaya aksial maksimum yang diderita satu borepile, Pmaks adalah $6564.5 \mathrm{kN}$ yakni pada kombinasi $\mathrm{V}$, sehingga kekuatan borepile menyisakan ratio persentase kekuatan sebesar $34.45 \%$.

Berdasarkan studi yang telah dilakukan pada stabilitas abutment jembatan pada Jalan Tol Pandaan - Malang Sta 15 + 916 terhadap pengaruh Gempa Sesuai dengan SNI 2833-2016 ini menyatakan bahwa stabilitas abutment jembatan dalam kondisi aman.

\section{Saran}

1. Penggunaan program bantu perangkat lunak diperlukan dalam analisis komponen jembatan yang lebih detil bagian gelagar jembatan serta abutment.

2. Untuk penelitian selanjutnya agar dapat diteliti mengenai kondisi - kondisi tanah pada abutment jembatan sesuai SNI 2833-2013 atau keadaan tanah pada saat menerima beban gempa terhadap struktur jembatan.

\section{DAFTAR PUSTAKA}

Badan Standarisasi Nasional. 2016.

Perencanaan untuk Jembatan. SNI 17252016 Jakarta.

Badan Standarisasi Nasional. 2013. Perencanaan Jembatan Terhadap Beban Gempa. RSNI T-2833-2013. Jakarta.

Badan Standarisasi Nasional. 2016. Perencanaan Jembatan Terhadap Beban Gempa. SNI 2833-2016. Jakarta.
Badan Standarisasi Nasional. 2008. Standar Perencanaan Ketahanan Gempa Untuk Jembatan. SNI 2833-2008. Jakarta.

Badan Standarisasi Nasional. 2017. SNI 84602017. Persyaratan Perancangan Geoteknik. SNI 8460-2017. Jakarta.

Brige Management System. 1992. Peraturan Perencanaan Teknik Jembatan. BMS 1992. Departemen PU Bina Marga.

Iqbal, M, S. 1995. Dasa-Dasar Jembatan Beton Bertulang. Departemen Pekerjaan Umum. Jakarta. 